\title{
AOR
}

Selected Papers of \#AolR2019:

The $20^{\text {th }}$ Annual Conference of the Association of Internet Researchers Brisbane, Australia / 2-5 October 2019

\section{'MARKING THEIR OWN HOMEWORK': TRUST AND AUDIENCE MEASUREMENT IN THE AUSTRALIAN DIGITAL ADVERTISING INDUSTRY}

\author{
Samuel Kininmonth \\ RMIT University
}

This paper examines how the Australian advertising industry discusses trust in the infrastructures of digital advertising. The advertising industry is undergoing a major change as digital advertising is increasingly dominated by new advertising technology (adtech) players and major tech companies such as Facebook and Google. These new companies which rely on automated systems of ad targeting, pricing and placement to control large amounts of digital advertising inventory and offer new more 'efficient' ways to micro-target advertising. Yet these companies have garnered reputations for misrepresenting their numbers; a problem compounded by Google and Facebook's reticence to supply the means for independent audience verification such as seen elsewhere in advertising. This has led to a high degree of mistrust from Australian advertisers. The Australian Association of National Advertisers (AANA, 2018) remarked that a 'key risk for advertisers is a lack of transparency in measurement and viewability' on digital platforms.

Digital advertising relies on automation to deliver and measure ads (Turow, 2011). This has led to major concerns about what is often termed 'ad fraud'. Broadly, ad fraud is when ads are recorded as delivered (and presumably paid for) despite not being seen (or heard) by the advertiser's intended target. There are myriad activities that fall under the umbrella term of ad fraud which can be undertaken by human and non-human actors (such as bots). Industry-commissioned studies estimate losses to ad fraud were 6.5 Billion USD in 2017 (Schiff, 2017). This has led to a certain degree of skepticism and mistrust of digital advertising inventory in the industry.

Consolidated advertising infrastructures owned by companies such as Google and Facebook are also subject to mistrust within much industry discourse. Facebook and Google are behemoths in the digital advertising industry and often discussed as unavoidable 'frenemies' within the industry. Neither company offers serious third-party Suggested Citation (APA): Kininmonth, S. (2019, October 2-5). 'Marking Their Own Homework': Trust and Audience Measurement in The Australian Digital Advertising Industry. Paper presented at AolR 2019: The $20^{\text {th }}$ Annual Conference of the Association of Internet Researchers. Brisbane, Australia: AolR. Retrieved from http://spir.aoir.org. 
auditing, leading many in the advertising industry to say that they are 'marking their own homework'. This hunch has been born out in the past with Facebook admitting in 2016 that it overestimated the popularity of video on the platform for two years because of a flawed metric (Vranica \& Marshall, 2016). Other parts of the advertising industry such as the multinational holding companies (WPP, Publicis etc.) use this as a point of differentiation between themselves and the tech giants, claiming greater independent oversight to elicit trust from advertisers.

Players in digital advertising have long promoted their automated systems as being more accountable as well as more efficient than previous advertising infrastructures (Turow, 2011). Ad verification has a long history from the publishing of newspaper circulation data, to radio diaries to television ratings (McFall, 2004). Major companies such as Nielsen_offer continuous or regular audience estimates which are often discussed with a high degree of trust in the industry.

At stake then, is trust in the infrastructures of audience measurement. Rather than examining the veracity of claims, I examine the way different actors deploy trust in these systems to achieve particular ends. Metrics are used as leverage within the highly contested space. Different players within the industry offer their customers measurement technologies designed to foster trust that the right people see the right ads for the right price. The trust in these measurements is fundamental to the companies involved in digital advertising.

Despite the significance of digital advertising as a major economic and infrastructural part of digital media and communication, it has tended not to attract the same degree of scholarship as other parts of media and communication. Much of the commendable work that has been done has tended to focus on the use of surveillance to target advertisements (Cohen, 2017; Turow, 2011). This is important work but there is more to be done in understanding the industry dynamics that surround surveillance. A major reason much digital advertising relies on the use of surveillance is that it may be seen to make the delivery of advertisements more reliable. More 'targets' and less 'waste' as the industry often describes it.

In this paper I ask, how is trust in measurement and verification infrastructures discussed within the Australian digital advertising industry? Is it fair to compare businesses that distribute advertising in very different ways? I answer these questions through qualitative analysis of submissions made to the Australian Competition and Consumer Commission (ACCC) as part of its current Digital Platforms Inquiry (DPI) in 2018 and 2019. I also draw on summaries of four public forums the ACCC held in 2018 as well as wide reading in the advertising industry trade press. This study sits within a larger project that examines the adoption of automation in the Australian digital advertising landscape.

Stakeholders made over 60 submissions the first of round of the DPI. The ACCC used the first round of submissions and forums to draft a preliminary report. The ACCC's preliminary report was non-committal on the subject of advertisement verification although the issue was raised in multiple submissions and the public forums. Both Google and Facebook claim that their ads are able to be verified. This is disputed by 
others who note that the verification is still based on Google and Facebook's data. The ACCC has requested further submissions from industry regarding ad verification and the second round of submissions are likely to be made public in March 2019. The final DPI report is due by June 2019. I will encompass those subsequent releases into the research on an ongoing basis and use them to better understand how the industry discusses issues ad verification and trust.

This paper aims to contribute to a better understanding of the debates within industry about trust and verification during industry transformation. These debates are important to see what role standards and measures play within the industry. While the infrastructures and dynamics of digital advertising are often hidden from the public gaze they have major effects on the broader media and communication they support (Turow \& Couldry, 2018). The advertising industry exercises a great degree of economic power in digital media and understanding its structures and logics can aid researchers when examining broader concerns for internet scholars. For example issues surrounding ad verification may bleed into other possible outcomes such as greater reliance on surveillance mechanisms to track users to the point of sale or broader data sharing arrangements to enable third-party compliance.

\section{References}

AANA (2018) Submission to ACCC: Digital Platforms Inquiry. Retrieved from https://www.acc..gov.au/system/files/Australian\%20Association\%20of\%20National\%20 Advertisers\%20\%28April\%202018\%29.pdf

Cohen, J. E. (2017). The Biopolitical Public Domain: the Legal Construction of the Surveillance Economy. Philosophy \& Technology. doi:10.1007/s13347-017-0258-2

McFall, L. (2004). Advertising: a cultural economy. London: Sage Publications Ltd.

Schiff, A. (2017). ANA/White Ops: Ad Fraud Will Actually Go Down In 2017, From \$7.2 Billion To \$6.5 Billion. Ad Exchanger. Retrieved from https://web.archive.org/web/20190220020841/https://adexchanger.com/ad-exchangenews/anawhite-ops-ad-fraud-will-actually-go-2017-7-2-billion-6-5-billion/

Turow, J., \& Couldry, N. (2018). Media as Data Extraction: Towards a New Map of a Transformed Communications Field. Journal of Communication, 68(2), 415-423. doi:10.1093/joc/jqx011

Turow, J. (2011). The Daily You: How The New Advertising Industry Is Defining Your Identity And Your Worth. New Haven: Yale University Press.

Vranica, S., \& Marshall, J. (2016). Facebook Overestimated Key Video Metric for Two Years. The Wall Street Journal. Retrieved from https://web.archive.org/web/20190220010121/https://www.wsj.com/articles/facebookoverestimated-key-video-metric-for-two-years-1474586951 